\title{
REFLECTION
}

\section{The Space in Between}

\author{
Christine Duffy, MD, MPH \\ Department of General Internal Medicine, Rhode Island Hospital/Brown University, Providence, RI, USA.
}

J Gen Intern Med 24(Suppl 2):429

DOI: $10.1007 / \mathrm{s} 11606-009-1090-\mathrm{x}$

(c) Society of General Internal Medicine 2009

$\mathrm{T}$ hree months into my medicine residency, my father was diagnosed with lung cancer. Previously he had eschewed my involvement in his medical care; once he was diagnosed all information and decisions were vetted by me. I was touched by his faith in me, but terrified because it reflected how frightened my father was by what was happening to him.

From the beginning, my father was clear that he did not want aggressive treatment if he had metastatic disease. Despite a CAT scan that showed bilateral adrenal masses, the oncologists pushed for aggressive treatment since my father was fairly young and healthy. Neither his doctors nor I were completely honest. The oncologists hid behind the difficulty of making the definitive diagnosis. I was in the middle of an ICU month and would like to rationalize my actions as delirium from lack of sleep. The truth was I could not deal with the idea that he would die. I clung to the small, unrealistic hope that his disease was not metastatic. My heart is still heavy when I recall convincing him, along with his physicians, to undergo chemo, radiation and surgery. I felt a sense of relief when he finally, reluctantly, agreed to proceed.

To this day, I don't fully understand why my dad's physicians did not seek definitive staging. I suspect they felt that he would be robbed of hope because of his determination to decline treatment if his disease was metastatic. I could not bear his "giving up," that he would die. As his daughter, I should have had the strength to honor his wishes, to allow him to make his own decisions about treatment. I should have pushed those physicians around me to be realistic and honest about his chances of survival and the costs, physical and mental, of aggressive treatment. In the end he suffered through months of debilitating radiation and chemotherapy, with intractable nausea and vomiting, and underwent a major surgery requiring a lengthy hospital stay. My father could deal with his disease and its consequences; sadly the oncologists and I were the ones who did not have the courage to face the truth.

Soon after my father's initial treatment, the adrenal masses began to grow and a biopsy confirmed that he had metastatic disease. His primary care physician pushed for bilateral adrenalectomy. Awakening from my internship haze, I suggested a second opinion. This physician, after talking with Dad, suggested waiting several months before considering surgery. Tacitly, we all understood what he was saying. When Dad decided to "take a break" from treatment, I did not try to stop him. He was able to take some short trips with my mother. Eventually, he developed brain metastasis and went home with hospice. He died peacefully, fully accepting his fate.

For anyone, there is no more terrifying time then when you face a life-threatening diagnosis. Having a physician in the family, someone who can help interpret and translate the medical system and their diagnosis, it can give back a sense of control during a time of helplessness. Having an "insider" to help maneuver through the system and make decisions can be an incredible support. But it is a tremendous burden, being a medical provider and being a loved one. The roles get all mixed up. You are never fully either. Instead of appropriately helping to interpret and understand the information provided, it is easy to conceal its true meaning out of your own fears and desires. The health professional who loses a loved one to cancer is, themselves, a sort of cancer survivor. The medical mistakes you make with your own family and friends haunt you in intense and unrelenting ways.

In the ten years since my father's death I am better at playing the dual role of being a physician and a loved one. I still struggle to ensure I separate my own wants, fears, and desires from those of my loved one. Although I have wanted at times to be only the "sister" or "daughter," I realize that this is neither possible nor fair. I have a responsibility to do my best to help navigate the medical system and manage that tricky place inbetween being a medical professional and loved one. 